\title{
Uso de resíduo de pneus inservíveis em substituição ao agregado fino em argamassa de revestimento
}

O descarte inadequado de pneus na natureza provoca efeitos nocivos ao meio ambiente no âmbito mundial pelo risco de contaminação ao ar, solo e lençol freático. Desta forma, com o intuito de reciclar o uso deste material, a pesquisa emprega substituições parciais em massa do agregado fino ( $15 \%$ e $25 \%$ ) por resíduo de borracha peneirada passante nas peneiras de $1,2 \mathrm{~mm}$ e retida na de $0,6 \mathrm{~mm}$ na produção de argamassas de revestimento. $O$ objetivo é avaliar a possibilidade do uso viável desta argamassa e para isso realiza os ensaios de resistência a compressão, absorção por capilaridade e avaliação do desempenho térmico. No estudo experimental foi definido o traço 1:3 e realizados ensaios de caracterização do material e aqueles de avaliação do desempenho da argamassa, conforme disposto na metodologia e de acordo com as normas específicas. A relação água/cimento definida foi de 0,70 para a referência e 0,63 para aquelas argamassas com substituições. A influência do resíduo de borracha de pneu na argamassa de revestimento, em comparação com a referência, mostra reduções na resistência a compressão, menores índices de absorção e capilaridade com o aumento do incremento de resíduo de borracha. A avaliação térmica revela maior redução na variação de temperatura após incidência de fonte térmica. Constatou-se, portanto, uso viável da argamassa de revestimento com substituição do agregado fino por resíduo de borracha principalmente com o foco de maior isolamento térmico para a construção.

Palavras-chave: Argamassa de revestimento; Borracha de pneu; Resíduo; Substituição; Sustentabilidade.

\section{Use of waste of waste tires to replace fine aggregate in lining mortar}

Inadequate disposal of tires in nature causes harmful effects on the environment worldwide due to the risk of contamination to air, soil and groundwater. Thus, in order to recycle the use of this material, the research employs partial bulk substitutions of the fine aggregate $(15 \%$ and $25 \%$ ) by sifted rubber residue passing through the $1.2 \mathrm{~mm}$ sieves and retained in the $0.6 \mathrm{~mm}$ production of coating mortars. The objective is to evaluate the possibility of the viable use of this mortar and for this it carries out the tests of resistance to compression, absorption by capillarity and evaluation of the thermal performance. In the experimental study, the 1: 3 traits were defined, and material characterization and mortar performance evaluation tests were performed, according to the methodology and in accordance with the specific standards. The water / cement ratio was 0.70 for the reference and 0.63 for those mortars with substitutions. The influence of the tire rubber residue on the coating mortar, compared to the reference, shows reductions in compressive strength, lower rates of absorption and capillarity with increasing increment of rubber residue. Thermal evaluation reveals greater reduction in temperature variation after thermal source incidence. It was verified, therefore, viable use of the mortar of coating with substitution of the fine aggregate by rubber residue mainly with the focus of greater thermal insulation for the construction.

Keywords: Coating mortar; Tire rubber; Residue; Substitution; Sustainability.

Topic: Engenharia Civil

Reviewed anonymously in the process of blind peer.

Leidian Aragão Torres

Universidade Federal do Rio Grande do Norte, Brasil http://lattes.cnpq.br/1628459124896179

leidian torres@yahoo.com.br

Maria Cecilia de Souza e Souza

Universidade Federal do Rio Grande do Norte, Brasil http://lattes.cnpq.br/4230583203852289

mariasouza.eng@outlook.com

Adna Lúcia Rodrigues de Menezes

Universidade Federal do Rio Grande do Norte, Brasil http://lattes.cnpq.br/5462600186457561

adnalucia@hotmail.com
Received: 11/07/2017

Approved: 12/10/2017
Kleber Cavalcanti Cabral

Universidade Federal Rural do Semiárido, Brasil

http://lattes.cnpq.br/8387906402114241

kleber.cabral@ufersa.edu.br
Referencing this:

TORRES, L. A.; SOUZA, M. C. S.; MENEZES, A. L. R.; CABRAL, K. C.. Uso de resíduo de pneus inservíveis em substituição ao agregado fino em argamassa de revestimento. Engineering Sciences, v.5, n.1, p.14-23, 2017. DOI: http://doi.org/10.6008/SPC2318-3055.2017.001.0002

DOI: 10.6008/SPC2318-3055.2017.001.0002 


\section{INTRODUÇÃO}

De acordo com a Associação Nacional da Indústria de Pneumáticos (ANIP, 2017), foi produzido no primeiro quadrimestre do ano corrente 22,6 milhões de unidades de pneus. Sua produção teve um aumento de $1,8 \%$ em relação ao ano de 2016 . Após o uso, o descarte inadequado desse material no meio ambiente leva mais de 100 anos para decompor totalmente.

Atesta-se, no Brasil, que enquanto houve evolução do aproveitamento de alguns resíduos sólidos nas últimas décadas, outros materiais tais como os pneus inservíveis e demais derivados da borracha, continuam sendo dispostos inadequadamente no meio ambiente. São vários os impactos que os pneus podem provocar ao meio ambiente, além do mais, os materiais presentes na sua composição estrutural são de difícil decomposição (RODRIGUES et al., 2010). O rejeito de borracha é classificado como resíduo classe III - inerte, por não conter metais pesados, não sofrer lixiviação e não ser solúvel em água (ABNT, 2004).

Buscando ajudar os recursos naturais e reduzir os impactos ambientais, diversos pesquisadores investigaram o uso de pneus reciclados com foco em aplicações como sistemas de impermeabilização, pavimentos de asfalto e revestimentos de membrana. (SIDDIQUE et al., 2004; CAO, 2007). Outra abordagem para a eliminação de resíduos de pneus é a incorporação desses resíduos de borracha em materiais à base de cimento. A literatura acerca do uso de partículas de borracha de pneu em materiais à base de cimento registra pesquisas que se concentram geralmente no uso de partículas de borracha de pneu como agregado grosso ou fino em concreto. E os resultados indicam que o concreto emborrachado possui menor densidade, maior tenacidade e ductilidade, menor resistência à compressão e à tração e isolamento acústico mais eficiente (SIDDIQUE et al., 2008).

Todavia há uma quantidade limitada de pesquisas sobre o uso de partículas de borracha de pneu como substituição ao agregado miúdo em argamassas de revestimento. Devido à escassez de estudos sobre uso do resíduo de pneu para produção de argamassas de revestimento e consequente minimização dos efeitos nocivos ao meio ambiente, o objetivo da pesquisa é avaliar a viabilidade do uso de resíduo de pneu em substituição ( $15 \%$ e $25 \%$ ) ao agregado fino (areia) e o estudo das propriedades de resistência a compressão, absorção de água por capilaridade e avaliação do desempenho térmico adquiridos quando comparadas às argamassas de referência.

\section{DISCUSSÃO TEÓRICA}

\section{Trabalhos anteriores}

Foi relatado que as argamassas com incorporação de fragmentos de borracha atingiram uma capacidade de trabalho compatível ou melhor do que uma argamassa de controle sem partículas de borracha (RAGHAVAN et al., 1998). A incorporação de agregados de borracha de pneus triturados em argamassas à base de cimento pode ser uma solução de controle de sua propensão à fissuração. As argamassas de borracha apresentam uma capacidade de deformação aprimorada e aumento do encolhimento livre (TURATSINZE et al., 2005, 2007). 
Nacif et al. (2012) realizaram uma pesquisa de compósitos cimentícios com inclusão de resíduos de borracha em frações de 0,84/0,58 mm e 0,28/0,18 mm, frações em massa na ordem de $5 \%, 15 \%$ e $30 \%$ e relação água/cimento de 0,35 e 50. Avaliando as propriedades físico-mecânicas constatou-se que a interação do tamanho das partículas de borracha, quantidade presente no compósito e relação a/c afetam significativamente na densidade e resistência do compósito, mostrando que quando a fração de borracha foi aumentada, a densidade aparente do compósito diminuiu devido à baixa densidade comparada a matriz de cimento. Contudo, essa baixa densidade da pasta de cimento emborrachada indica ser vantajosa para produção de compósitos com isolante térmico e acústico.

Angelin et al. (2015) concentraram seus experimentos na investigação da resistência/porosidade em pasta de cimento e argamassa com resíduo de borracha em função da morfologia dos grãos de borracha (4 formulações). Foi observado que o aumento da porosidade causa uma diminuição da resistência à compressão, ou seja, a interrelação entre a resistência e porosidade se mostrou inversa. Todavia, os resultados indicaram que as argamassas com $5 \%$ de borracha na sua composição apresentaram propriedades interessantes para diversas aplicações na engenharia.

\section{MATERIAIS E MÉTODOS}

\section{Caracterização dos materiais}

A areia utilizada na fabricação da argamassa caracteriza-se como média, peneirada, lavada e seca em estufa por 24h. A massa específica da areia encontrada pelo ensaio do Frasco de Chapman, NBR 9776/1987, foi $2,625 \mathrm{~g} / \mathrm{ml}$. Quanto a distribuição granulométrica, a areia possui valores de módulo de finura e dimensão máxima característica correspondente a 2,57 (zona ótima) e 4,8 mm, respectivamente. A massa unitária da areia adotada da literatura equivale a $1,51 \mathrm{~g} / \mathrm{ml}$.

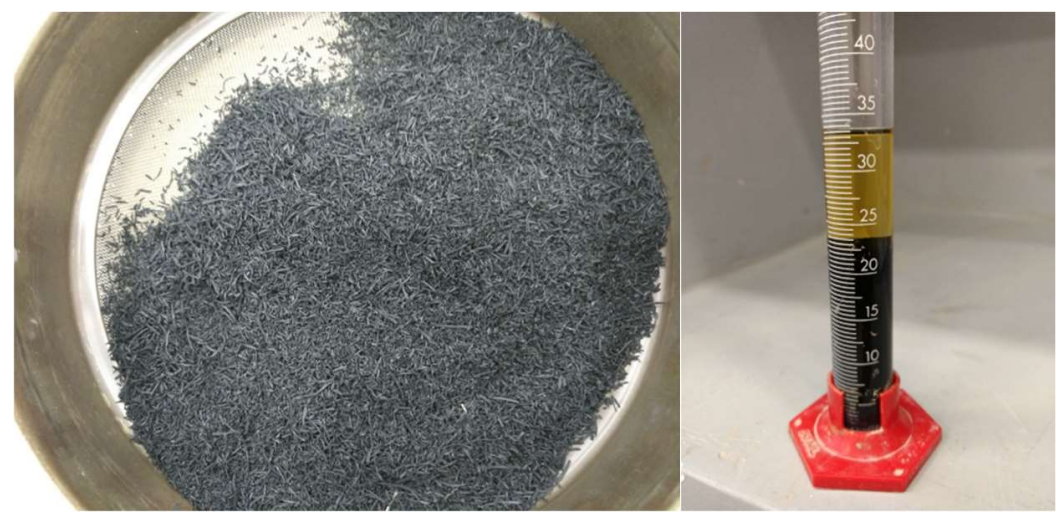

(a)

(b)

Figura 1: Resíduo da borracha usada no estudo e Ensaio de massa específica adaptado para o resíduo.

O cimento utilizado no estudo era o cimento Portland Comum (PC) CP IV 32 Pozolânico. A massa específica encontrada em laboratório a partir do ensaio de Le Chatelier conforme norma NBR NM 23/2001 foi de $2,857 \mathrm{~g} / \mathrm{ml}$. O resíduo de borracha de pneu utilizado na pesquisa foi obtido da trituração mecânica de resíduos de pneus inservíveis de automóveis. O diâmetro das partículas foi definido como o resíduo passante na peneira de malha $1,2 \mathrm{~mm}$ e retido na de $0,6 \mathrm{~mm}$. A Figura 1a mostra a fração de borracha usada no estudo. 
Não há normatização própria para a obtenção da massa específica e unitária do resíduo da borracha. Sendo assim, sabendo se que a massa específica é a relação da massa com o volume sem vazios, foi feita uma adaptação do Ensaio do Frasco Chapman, com uso de uma proveta bem graduada, conforme a figura 1b. A massa específica encontrada foi de $1,11 \mathrm{~g} / \mathrm{ml}$. Por outro lado, para o ensaio de massa unitária da borracha, que relaciona massa e volume de material solto, foi adaptado do ensaio de massa unitária da areia, obteve valor igual a $0,343 \mathrm{~g} / \mathrm{ml}$. Os valores de massa específica e unitárias de todos os materiais são apresentadas na Tabela 1.

Tabela 1: Massas específicas e unitárias dos materiais ensaiados.

\begin{tabular}{|l|c|c|}
\multicolumn{1}{|c|}{ Material } & Massa específica $(\mathrm{g} / \mathrm{ml})$ & Massa unitária $(\mathrm{g} / \mathrm{ml})$ \\
\hline Cimento & 2,857 & - \\
\hline Areia & 2,625 & 1,51 \\
\hline Resíduo de borracha & 1,11 & 0,343 \\
\hline
\end{tabular}

\section{Definições do traço}

O traço foi definido nas proporções 1:3 em massa e tem como finalidade o uso em argamassa de revestimento. A mistura dos componentes da argamassa deu-se em duas substituições, $15 \%$ e $25 \%$ de massa de areia pelo equivalente em volume de borracha. A escolha desse método de substituição deve-se ao fato de as partículas de borracha apresentarem massa unitária igual a $0,343 \mathrm{~g} / \mathrm{ml}$, ou seja, se a substituição fosse em massa de areia por massa de borracha, o volume incorporado de borracha seria bastante elevado em relação ao retirado de areia. No cálculo das substituições foi usado a massa unitária da areia e da borracha. O cálculo do consumo dos materiais é com base nos valores de massa específica do cimento e da areia obtidos na caracterização.

O índice de consistência da argamassa de revestimento, segundo NBR 13276/2016, deverá ser de $255 \mathrm{~mm} \pm 10 \mathrm{~mm}$. Com base na quantidade de água adicionada na mistura é calculado o fator a/c para argamassa de referência, substituições de $15 \%$ e $25 \%$. Os resultados obtidos foram 0,70 e 0,63, respectivamente.

\section{Ensaios a serem avaliados}

Para a execução do ensaio de resistência a compressão, conforme a NBR 13279/2005, foram preparados 4 corpos de prova cilíndricos de dimensões $5 \mathrm{~cm} \times 10 \mathrm{~cm}$ para cada traço. A moldagem foi realizada em 2 camadas, compactando-se com um soquete em 12 golpes. Depois da moldagem, os espécimes foram curados ao ar, durante 21 dias, até o momento do ensaio de compressão.

O ensaio para determinação da absorção de água por capilaridade e do coeficiente de capilaridade seguiu o procedimento indicado na norma NBR 15259/2005, realizados em 3 corpos de prova prismáticos para cada traço, moldados em 2 camadas compactadas com 30 golpes de soquete cada. Inicialmente as superfícies dos corpos de prova foram lixadas e limpas com pincel, em seguida determinou-se a massa inicial de cada um. Posteriormente os corpos de prova foram posicionados com a face quadrada sobre uma malha

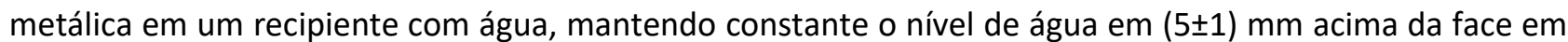


contato com a água, conforme a figura 7. Após imersos foi determinada a massa de cada um deles aos 10 minutos e aos 90 minutos. Depois das medições as amostras foram secas em estufa por $36 \mathrm{~h}$ e repetidos os procedimentos.

Segundo a ABNT (2003), o atraso térmico representa o tempo decorrido entre uma variação térmica em um meio e sua manifestação na superfície oposta de um componente construtivo submetido a um regime periódico de transmissão de calor. O ensaio de atraso térmico das argamassas foi realizado em um caixote de madeira com as seguintes dimensões: $46 \mathrm{~cm}$ (altura) $\times 60 \mathrm{~cm}$ (largura) x $80 \mathrm{~cm}$ (comprimento) com 1 fonte de luz emanando calor. Para cada traço foi executado uma placa com dimensões de $11 \mathrm{~cm}$ (largura) x 19,5cm (comprimento) $\times 3 \mathrm{~cm}$ (espessura). A avaliação do atraso térmico foi feita com sensores internos (Si) e externos (Se) ligados as faces transversais a fonte de calor. As outras faces foram isoladas termicamente com isopor, como ilustra a Figura 2. Foi coletado as temperaturas internas e externas das faces transversais de cada placa no tempo inicial (t0) e nos tempos (ti) de $1 \mathrm{~min}, 2 \mathrm{~min}, 3 \mathrm{~min}, 4 \mathrm{~min}, 5 \mathrm{~min}, 10 \mathrm{~min}, 15 \mathrm{~min}, 20 \mathrm{~min}$, $25 \mathrm{~min}, 30 \mathrm{~min}, 35 \mathrm{~min}$ e $40 \mathrm{~min}$.

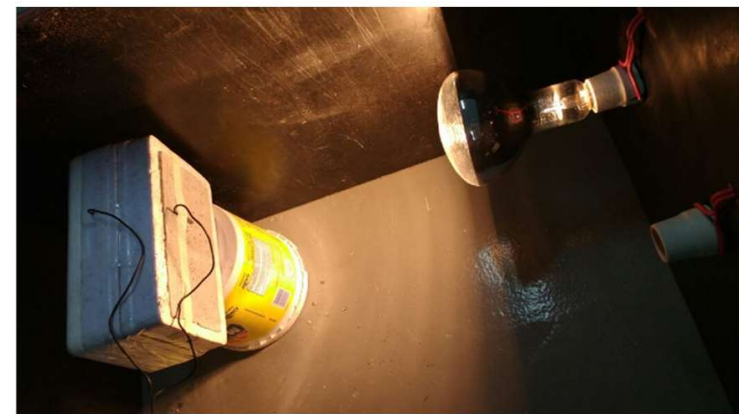

(a)

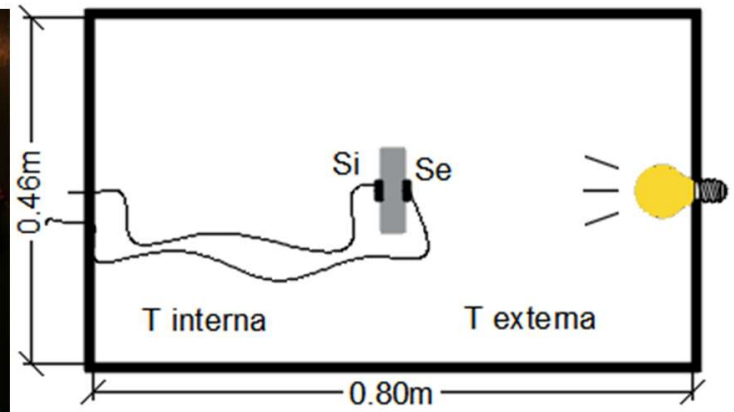

(b)

Figura 2: Ensaio de avaliação térmica e Esquema do ensaio - vista lateral.

\section{RESULTADOS E DISCUSSÕES}

\section{Ensaio de resistência a compressão}

A resistência a compressão aos 21 dias em função da porcentagem de substituição de borracha é ilustrada na figura 3. Os resultados indicaram que houve uma redução na resistência a compressão com o aumento do percentual de borracha em comparação com a argamassa de referência. A resistência a compressão da argamassa de referência foi avaliada em 11,363 MPa. As reduções na resistência das argamassas de substituição foram de $29,75 \%$ e $60,99 \%$ para as substituições de $15 \%$ e $25 \%$, respectivamente. Estudos anteriores também indicaram redução na resistência a compressão com o aumento de borracha, além de influência do tamanho, proporções e texturas da superfície da borracha (YILMAZ et al., 2009).

A resistência dos materiais cimentícios é atribuída também as forças de Van der Waals do Silicato de Cálcio Hidratado (CSH), que compõe de 50 a 60\% do volume de sólidos. A aderência entre duas superfícies pode ser atribuída a essas forças (MEHTA et al., 2008). 0 acréscimo de borracha de pneu reduz a aderência entre as superfícies cimentícias e a areia, e consequentemente a resistência das argamassas. A borracha possui rigidez menor, quando comparada a pasta de cimento. 
A figura 4 mostra os corpos de prova após a realização do ensaio de resistência a compressão. Os CP's (corpos de prova) das argamassas com substituições mostraram fraturas mais acentuadas quando comparados aos de referência, sendo o de substituição de $25 \%$ menos íntegro fisicamente. Diferentemente dos estudos de Khatib et al. (1999) citados por Yilmaz et al. (2009) que indicaram nos CP's com presença de borracha uma maior deformação, porém sem completa desintegração, devido a ancoragem das fibras da borracha na matriz do cimento. Essa diferença nos resultados pode ser atribuída aos diferentes tamanhos de borracha utilizados nos estudos.

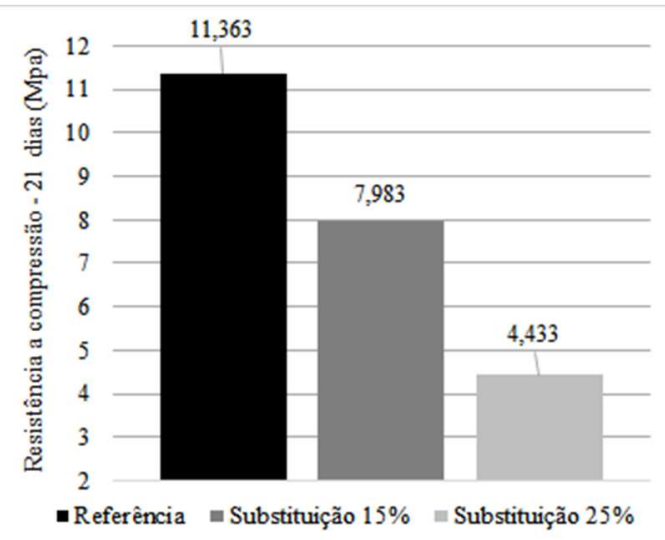

Figura 3: Resultados médios da resistência a compressão (21 dias) das argamassas.

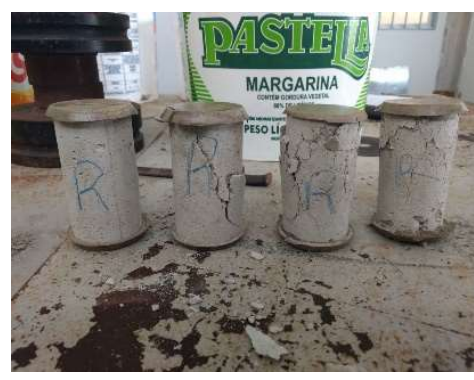

(a)

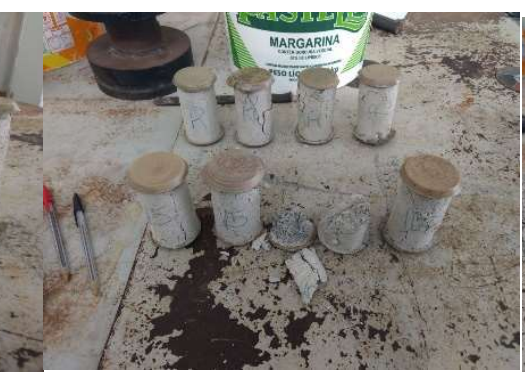

(b)

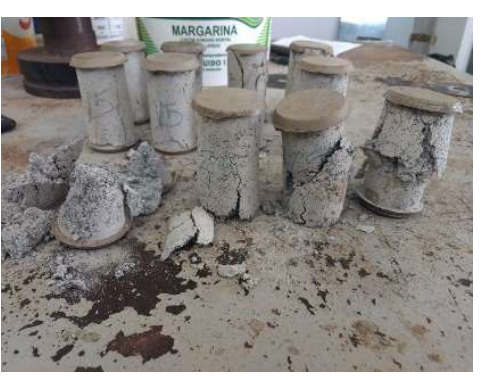

(c)

Figura 4: Corpos de prova após ensaio o ensaio de resistência a compressão: (a) Referência; (b) Substituição de 15\% e (c) Substituição de $25 \%$.

\section{Determinação da absorção de água por capilaridade e ensaio do coeficiente de capilaridade}

A absorção por capilaridade aos 28 dias em função da porcentagem de substituição de borracha é ilustrada na Figura 5. Os resultados indicaram que as argamassas com adição de borracha apresentaram valores menores de absorção por capilaridade quando comparadas com a argamassa de referência. Ambas as substituições apresentaram desempenho parecido quanto a absorção de água, tendo o melhor resultado o percentual de $25 \%$.

$\mathrm{Na}$ argamassa endurecida, a absorção de água e o coeficiente de capilaridade são controlados pelo tamanho e continuidade dos poros. O volume e o tamanho desses vazios capilares são determinados pela relação água/cimento e o grau de hidratação do cimento (MEHTA et al., 2008). Uma hipótese para essa diminuição da absorção é o fato da borracha ser impermeável, como diz Segre et al. (2000), também pode se considerar a interferência da borracha na continuidade dos poros visto que ela pode ser considerada agregado fino devido a sua granulometria. Outra possível justificativa é o valor da relação água/cimento ser 
menor que do traço de referência, fato que contribui para diminuição da quantidade de poros e consequentemente da capilaridade.

O ensaio realizado com os corpos de prova secos em estufa não demonstrou diferenças significativas nos índices de absorção por capilaridade da argamassa para os traços contendo borracha quando comparado com o ensaio antes da estufa. $O$ traço de referência apresentou diminuição significativa da absorção aos 10 minutos quando comparado com o ensaio antes da estufa, mas não significativa aos $90 \mathrm{~min}$. A redução nos valores de capilaridade após a colocação na estufa indica que havia umidade, mesmo que pouca, nos corpos de prova.

O coeficiente de capilaridade teve comportamento parecido com a absorção, assumindo valores bem menores para os traços com borracha na sua composição e próximos entre si, como pode ser visualizado na figura 6. Quando comparado os resultados dos ensaios antes e pós estufa, nota-se que os valores de capilaridade para os corpos de prova secos em estufa foram maiores que antes da secagem, com destaque para o traço de referência.

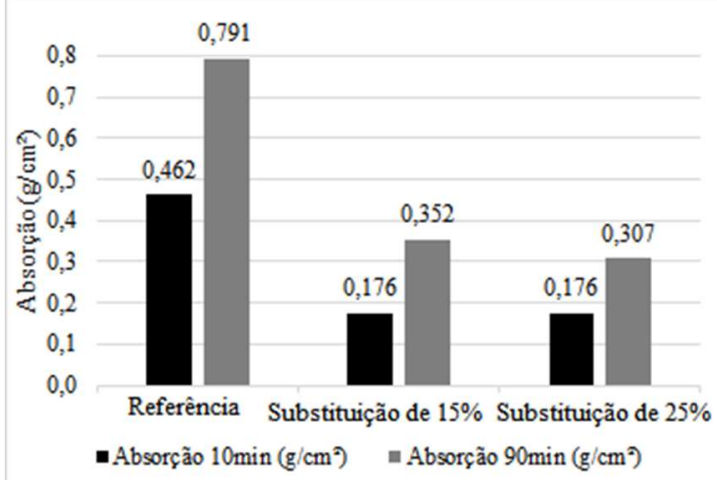

(a)

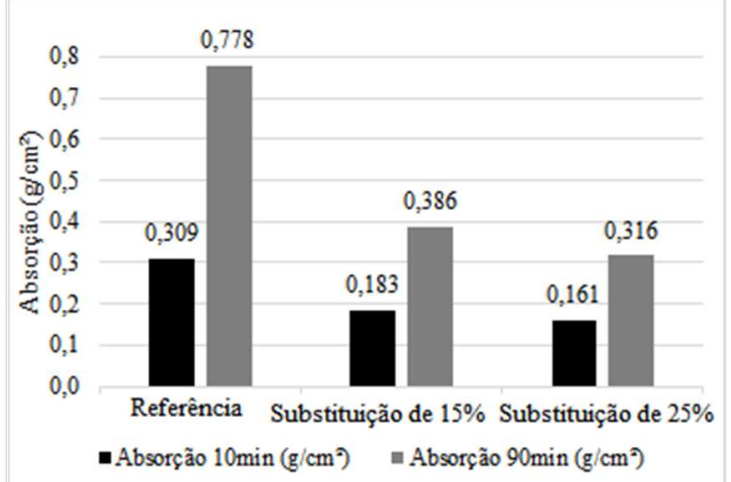

(b)

Figura 5: Resultados médios da absorção de água: antes da estufa; depois da estufa.

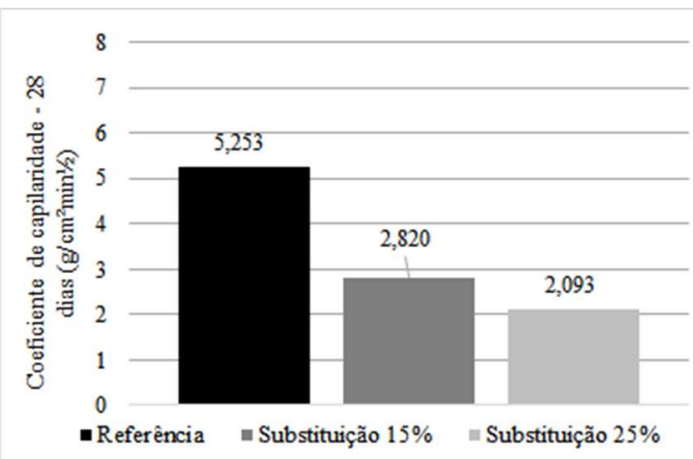

(a)

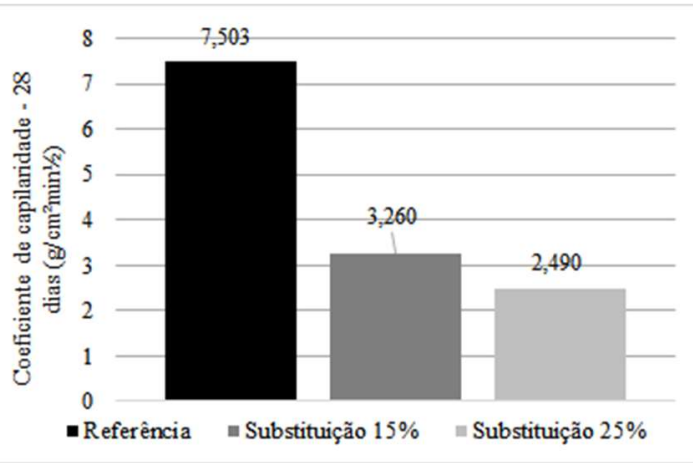

(b)

Figura 6: Resultados médios do coeficiente de capilaridade: (a) antes da estufa; (b) depois da estufa. 


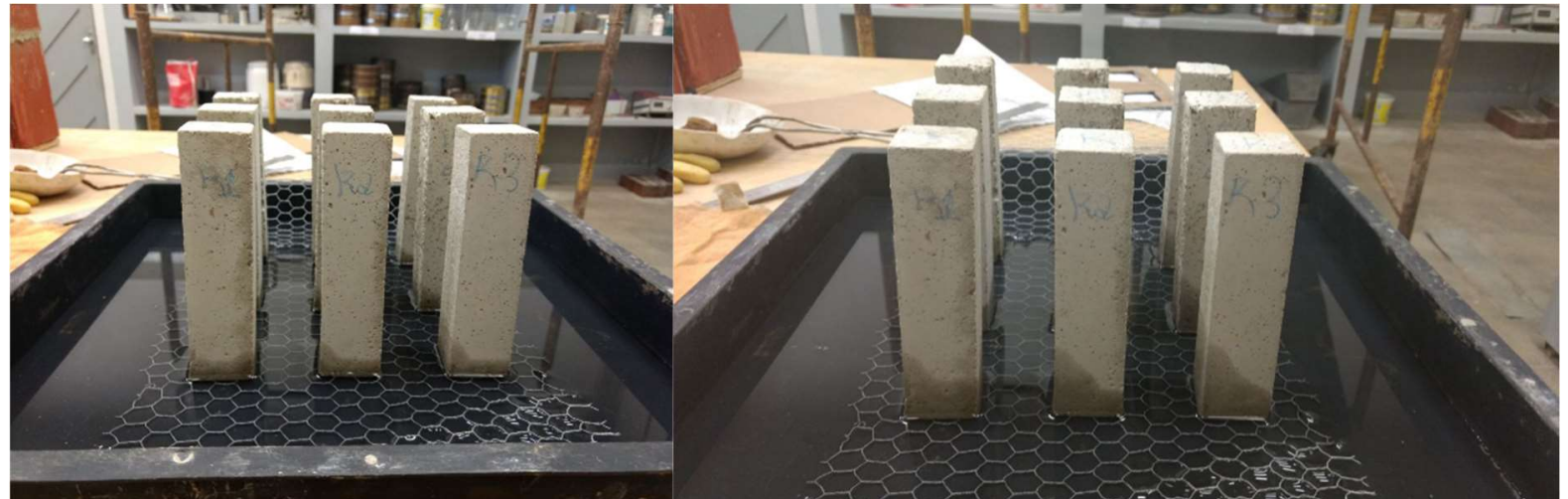

(a)

Figura 7: Ensaio de determinação da absorção de água por capilaridade e ensaio do coeficiente de capilaridade: 10 $\min ; 90 \mathrm{~min}$.

\section{Avaliação térmica}

A avaliação do atraso térmico para os três traços estudados é ilustrada na Figura 8. Os resultados indicam que a variação de temperatura ( $\Delta$ text - $\Delta$ tint) é menor para a argamassa de referência, caracterizando maior transmissão de calor através da placa que não possui borracha na sua composição. A argamassa de referência apresenta maior valor de diferença, 2,6 graus, no tempo 40 (minutos). Isso indica que o material possui uma condutividade térmica maior em relação as outras placas, ou seja, as variações da temperatura exterior são transmitidas aos espaços interiores com maior facilidade.

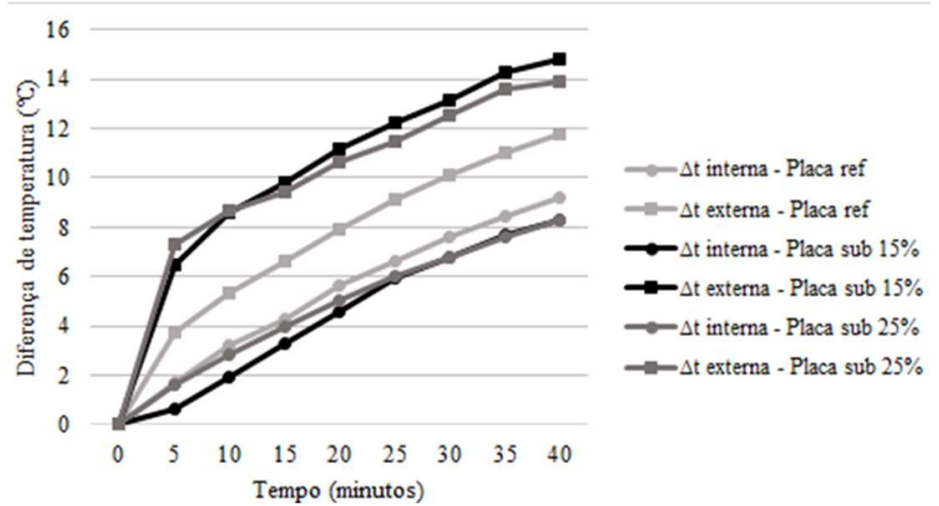

Figura 8: Variações de temperatura interna e externa dos tipos de placa versus Tempo.

Para as argamassas contendo borracha de pneu na sua composição, os resultados foram sensivelmente diferentes, apontando menor transmissão de calor através das placas com borracha. Tendo a placa com substituição de $15 \%$ variação levemente superior quando comparada a placa com substituição de 25\%. Isso confirma que a borracha de pneu proporciona a argamassa redução da transmissibilidade de calor, o que já foi indicado na seção de trabalhos anteriores.

Segundo Koksal et al. (2015), o uso de agregados leves em argamassas exerce o desenvolvimento de materiais de densidade reduzida, contribuindo com propriedades de isolamento térmico, acústico, assim como na redução do peso próprio. Carasek (2010) relaciona a espessura do revestimento com a sua capacidade de isolação térmica. E a condutividade térmica varia de acordo com a densidade do material e o tamanho das células (MENDES, 2002). Desta forma, destaca-se a argamassa com 15\% de resíduo de pneu 
substituindo a areia, por apresentar maior variação na redução da temperatura, mostrando-se vantajosa por apresentar características térmicas satisfatórias quando comparada a argamassa convencional.

\section{CONCLUSÕES}

A substituição de areia por fibra de borracha de pneu inservível em argamassa de cimento e areia para revestimento, pode levar a obtenção de um composto modificado com propriedades relevantes. As principais conclusões e diagnósticos do estudo da incorporação de borracha em argamassa, observadas a partir dos experimentos, foram:

A presença de borracha casou redução nos valores de resistência a compressão, diminuindo a resistência com o aumento do incremento de borracha;

A substituição de areia por borracha produziu índices menores de absorção por capilaridade, com valores próximos entre as substituições de 15\% e 25\%;

As argamassas com borracha na composição apresentaram menor capacidade de conduzir calor, com valores próximos para as substituições de $15 \%$ e $25 \%$;

A substituição em volume equivalente da massa de agregado suprimida apresentou excelente aplicabilidade;

A substituição de areia por borracha de pneu mostrou-se interessante para aplicação como revestimento, sendo necessários mais estudos para comprovar sua eficácia; e

O uso do resíduo de borracha nas argamassas de revestimento como substituição, além de permitir a retirada de parte dos pneus da natureza, ainda permite que o agregado miúdo retirado da natureza seja em menor quantidade.

A quantidade de ensaios realizados limita um diagnóstico mais profundo e assertivo sobre a utilização da composição estudada. Assim, sugere-se para trabalhos futuros utilizando fibra de borracha de pneu inservível os seguintes experimentos:

Realizar ensaio de aderência, resistência a tração e flexão para melhor caracterização e avaliação da argamassa resultante;

Comparar diferentes granulometrias dos resíduos para os mesmos teores de substituição; Estudar as propriedades para teores de substituições diferentes de 15\% e 25\%;

Determinação da porosidade (para relacionar a capilaridade com a resistência);

Realizar ensaios mais específicos para avaliar a microscopia do material (MEV);

Avaliação da argamassa submetido a ataques químicos e testes de durabilidade.

\section{REFERÊNCIAS}

ANIP. Associação Nacional da Indústria de Pneumáticos. Resultados dos fabricantes nacionais de pneus 10 quadrimestre de 2017. São Paulo: ANIP, 2017.

ANGELIN, A. F.; ANDRADE, M. F. F.; BONATTI, R.; LINTZ, R. C. C.; GACHET, B. L. A.; ÓSORIO, W. R.. Effects of spheroid and fiber like waste-tire rubbers on interrelation of strength-to-porosity in rubberized cement and mortars. Construction and Building Materials, v.95, 2015.
ABNT. Associação Brasileira de Normas Técnicas. Desempenho térmico de edificações: Definições, símbolos e unidades. Rio de Janeiro: ABNT, 2003.

ABNT. Associação Brasileira de Normas Técnicas. Argamassa para assentamento e revestimento de paredes e tetos: Determinação da absorção de água por capilaridade e do coeficiente de capilaridade. Rio de Janeiro: ABNT, 2005.

ABNT. Associação Brasileira de Normas Técnicas. Cimento Portland e outros materiais em pó: 
Determinação da massa específica. Rio de Janeiro: ABNT, 2001.

ABNT. Associação Brasileira de Normas Técnicas. Argamassa para assentamento e revestimento de paredes e tetos: Determinação do índice de consistência. Rio de Janeiro: ABNT, 2016.

ABNT. Associação Brasileira de Normas Técnicas. Argamassa para assentamento e revestimento de paredes e tetos: Determinação da resistência à tração na flexão e à compressão. Rio de Janeiro: ABNT, 2005.

ABNT. Associação Brasileira de Normas Técnicas. Agregados: Determinação da massa específica de agregados miúdos por meio do frasco Chapman. Rio de Janeiro: ABNT, 1987.

ABNT. Associação Brasileira de Normas Técnicas. Resíduos Sólidos. Rio de Janeiro: ABNT, 2004.

CAO, W.. Study on properties of recycled tire rubber modified asphalt mixtures using dry process.

Construction and Building Materials, v.21, 2007.

CARASEK, H.. Argamassas. In: Materiais de Construção Civil e Princípios de Ciência e Engenharia de Materiais. 2 ed. São Paulo: IBRACON,2010.

KOKSAL, F.; GENCEL, O.; KAYA, M.. Combined effect of silica fume and expanded vermiculite on properties of lightweight mortars at ambient and elevated temperatures. Construction and Building Materials, 2015.

MEHTA, P. K.; MONTEIRO, P. J. M.. Concreto: microestrutura, propriedades e materiais. São Paulo: IBRACON, 2008.

MENDES, J. U. L.. Desenvolvimento de um compósito biodegradável para isolamento térmico. Tese (Doutorado) - Universidade Federal do Rio Grande do Norte, Natal, 2002.
NACIF, G. L.; PANZERA, T. H.; STRECHER, K.; CHRISFOFORO, A. L.; PAINE, K.. Investigations on cementitious composites based on rubber particle waste additions. Materials Research, v.16, 2013.

RAGHAVAN, D.; HUYNH, H.; FERRARIS, C. F.. Workability, mechanical properties and chemical stability of a recycled tire rubber-filled cementitious composite. Journal of Materials Science, v.33, 1998.

RODRIGUES, M. R. P.; FERREIRA, O. P.. Compósito cimentício com adição de partículas de borracha de pneus inservíveis. Minerva, v.6, n.3, 2010.

SEGRE, N.; JOEKES, I.. Use of tire rubber particles as addition to cement paste. Cement and Concrete Research, Amsterdã, 2000.

SIDDIQUE, R.; KHATIB, J.; KAUR, I.. Use of recycled plastic in concrete: a review. Waste Management, v.28, 2008.

SIDDIQUE, R.; NAIK, T. R. Properties of concrete containing scrap-tire rubber: an overview. Waste management, v.24, 2004.

TURATSINZE, A.; BONNETS, J.; GRANJU J. L.. Mechanical characterization of cement based mortar incorporating rubber aggregates from recycled worn tyres. Building and Environment, v.40, 2005.

TURATSINZE, A.; BONNETS, J.; GRANJU J.-L. Potential of rubber aggregates to modify properties of cement based-mortars: improvement in cracking shrinkage resistance. Construction and Building Materials, v.21, 2007.

YILMAZ, A.; DEGIRMENCI, N.. Possibility of using waste tire rubber and fly ash with Portland cement as construction materials. Waste management, v.29, 2009. 